\title{
Carta al editor. \\ ¿Se deben investigar los factores de riesgo para COVID-19 ante la probabilidad que sea endémica?
}

\author{
DOI 10.5377/alerta.v4i2.11058 \\ Javier Isaac Molina Velásquez ${ }^{1}$, Susana Patricia Erazo Salas ${ }^{2}$ \\ 1. y 2. Hospital Regional ISSS, San Miguel, San Miguel, El Salvador y Hospital Nacional “Dr. Jorge Arturo Mena”, Santiago de María, \\ Usulután, El Salvador. \\ ${ }^{*}$ Correspondencia \\ $\checkmark$ javier_molina100@hotmail.com
}

(D) 0000-0002-0520-2707

\section{ACCESO ABIERTO}

Should COVID-19 risk factors be researched if it turns endemic?

Citación recomendada: Molina Velásquez JI, Erazo S. COVID-19: iSe deben investigar los factores de riesgo para COVID-19 ante la probabilidad que sea endémica? Alerta. 2021;4(2):8081. DOI: $10.5377 /$ alerta. v4i2. 11058

Recibido:

23 de marzo de 2021

\section{Aceptado:}

10 de mayo 2021

\section{Publicado:}

21 de mayo 2021

\section{Contribución de autoría: Ambos declaran trabajar en partes iguales.}

\section{Conflicto de intereses:}

Los autores declaran no tener conflicto de interés.

\section{Sr. Editor.}

El 31 de diciembre de 2019 la OMS notificó un brote de casos de neumonía de etiología desconocida en Wuhan, provincia de Hubei, China. El agente causal se identificó como una nueva cepa de coronavirus, que estaba infectando a miles de personas alrededor del mundo. Ante esta situación, el Gobierno de El Salvador decretó emergencia sanitaria el 23 de enero de 2020 por la probable llegada de casos sospechosos de COVID-19, anunciándose su primer caso el 18 de marzo ${ }^{1}$. Ante esta realidad; la constante investigación y publicación de artículos relacionados a esta patología, determina la eficacia en los tratamientos terapéuticos y medidas sanitarias necesarias en pro de la reducción de morbimortalidad en grupos de riesgo.

La COVID-19 es un problema de salud pública por el gran impacto que ha generado a nivel mundial. Ha provocado crisis en el sistema sanitario tanto de países desarrollados como en desarrollo, afectando ampliamente a estos últimos. Además, ha sido un desafío en la economía y la medicina a nivel mundial.

El aparecimiento de enfermedades data desde los orígenes del hombre. Por lo tanto, erradicar una enfermedad ha sido la meta de la medicina moderna, gracias al aparecimiento de la asepsia y antisepsia, las técnicas de esterilización, los antibióticos, las vacunas y sobre todo con el conocimiento de la fisiopatología de la enfermedad². Por ello, se considera importante investigar los factores de riesgo asociados al desarrollo de la COVID-19 en la población salvadoreña, pues esto permitirá mejorar el enfoque preventivo para dicha enfermedad.

Para esto, se debe fomentar la cultura de la investigación en el país, de tal manera que se puedan obtener datos propios, para posteriormente analizarlos y plantear propuesta de acciones que permitan realizar un enfoque preventivo de diversas enfermedades, priorizando la pandemia que abate al mundo actualmente. Entre las variables que se pueden estudiar en El Salvador se encuentran: edad (años desde el nacimiento hasta el aparecimiento de la enfermedad), sexo (determinación biológica del género), la presencia de comorbilidades (enfermedad asociada a un sistema mayor del organismo), estado nutricional (sobrepeso y obesidad). Todas ellas asociadas con la forma de presentación de COVID-19, a partir de la presencia de signos y síntomas de la enfermedad y otras complicaciones relacionadas que pudieran manifestarse en mayor o menor medida según grupos de riesgo y resultados de la aplicación de protocolos terapéuticos actualizados basados en evidencia científica, siguiendo las pautas éticas.

La edad es un dato bien importante en esta enfermedad. En El Salvador ha sido más afectado el rango entre 20 a 39 años de edad; seguida por la población de 40 a 
59 años en relación con la mayoría de casos positivos. Pero este dato podría deberse a la mayoría de casos reportados como asintomáticos o con síntomas leves. Estos rangos de edad podrían corresponder a mayor exposición en el grupo etario de la población económicamente activa, aunque esta relación al momento representa una mera inferencia. La página web oficial del Gobierno de El Salvador, que es el único medio legal y disponible para adquirir información, reporta los fallecidos; sin embargo, no se pueden visualizar las edades específicas o rangos de edad y las características asociadas (comorbilidades) de las personas en estado crítico y fallecidas.

Durante el desarrollo de la enfermedad, varios estudios han identificado factores como la edad, el sexo, la presencia de comorbilidades asociados al incremento en la tasa de mortalidad de los pacientes con COVID-193.

Es importante investigar otros factores de riesgo, propios del contexto salvadoreño, principalmente en personas con enfermedades inmunológicas, en quienes se presentaron complicaciones que los llevaron a una estancia prolongada en la unidad de cuidados intensivos en los centros hospitalarias de tercer nivel.

Ante esta situación, existe la necesidad de realizar estudios en el país que documenten los distintos factores de riesgo para el desarrollo de la COVID-19, para poder iniciar acciones preventivas sobre la población vulnerable que se identifique.

Se debe, además, tomar en cuenta la presencia de diferentes enfermedades específicas que afectan los distintos órganos y también hábitos deletéreos como el tabaquismo, que permita contrastar los datos globales, con los presentes en la población.

Hay estudios que sugieren un posible comportamiento endémico de la enfermedad y ante el subsecuente aparecimiento de nuevas cepas, se vuelve crucial establecer estrategias preventivas para la reducción de complicaciones y muertes por COVID-19. Dentro de las medidas actuales se encuentran la administración de pruebas, identifi- car los pacientes con factores de riesgo que los puedan llevar a presentar complicaciones, mantener el distanciamiento social ${ }^{4}$, así como la aplicación de una vacuna eficaz, con una adecuada cobertura de inmunización.

Sin embargo, aún hay brechas de conocimiento que podrán abordarse si se impulsa la investigación científica en el diario vivir y si el personal de salud incorpora estos resultados en la implementación de medidas preventivas y tratamientos que mejoren la salud de la población 5 .

El Salvador tiene suficiente material para el desarrollo de investigaciones sobre la enfermedad por COVID-19. A más de un año de los primeros casos confirmados, se pueden desarrollar estudios retrospectivos, con asociación a factores de riesgo que podrían aportar evidencias y preparar al país para prevenir los contagios y la enfermedad, pues se desconoce cuánto tiempo se estará conviviendo con el virus SARS-COV-2 y si llegará a volverse endémico en algunas regiones.

\section{Referencias bibliográficas}

1. López A, Domínguez R. Medidas de contingencia ante el COVID-19 en El Salvador, Alerta. 2021;4(1):78-79. DOI: 10.5377/alerta.v4i1.10762.

2. Akin L, Gözel MG. Understanding dynamics of pandemics. Turk J Med Sci. 2020 Apr 21;50(SI-1):515-519. DOI: 10.3906/sag-2004133.

3. Li J, Huang DQ, Zou B, Yang H, Hui WZ, Rui F, et. al. Epidemiology of COVID-19: A systematic review and meta-analysis of clinical characteristics, risk factors, and outcomes. J Med Virol. 2021 Mar;93(3):14491458. DOI: 10.1002/jmv.26424.

4. Choi W, Shim E. Optimal strategies for social distancing and testing to control COVID-19. J Theor Biol. 2021 Mar 7;512:110568. DOI: 10.1016/j.jtbi.2020.110568.

5. Sandoval López X. El reto de avanzar hacia una cultura de publicación científica. Alerta 2020;3(1):1-2. DOI: 10.5377/ alerta.v3i1.9275. 